\title{
Российское - значит отличное! Состояние и перспективы отечественного приборостроения
}

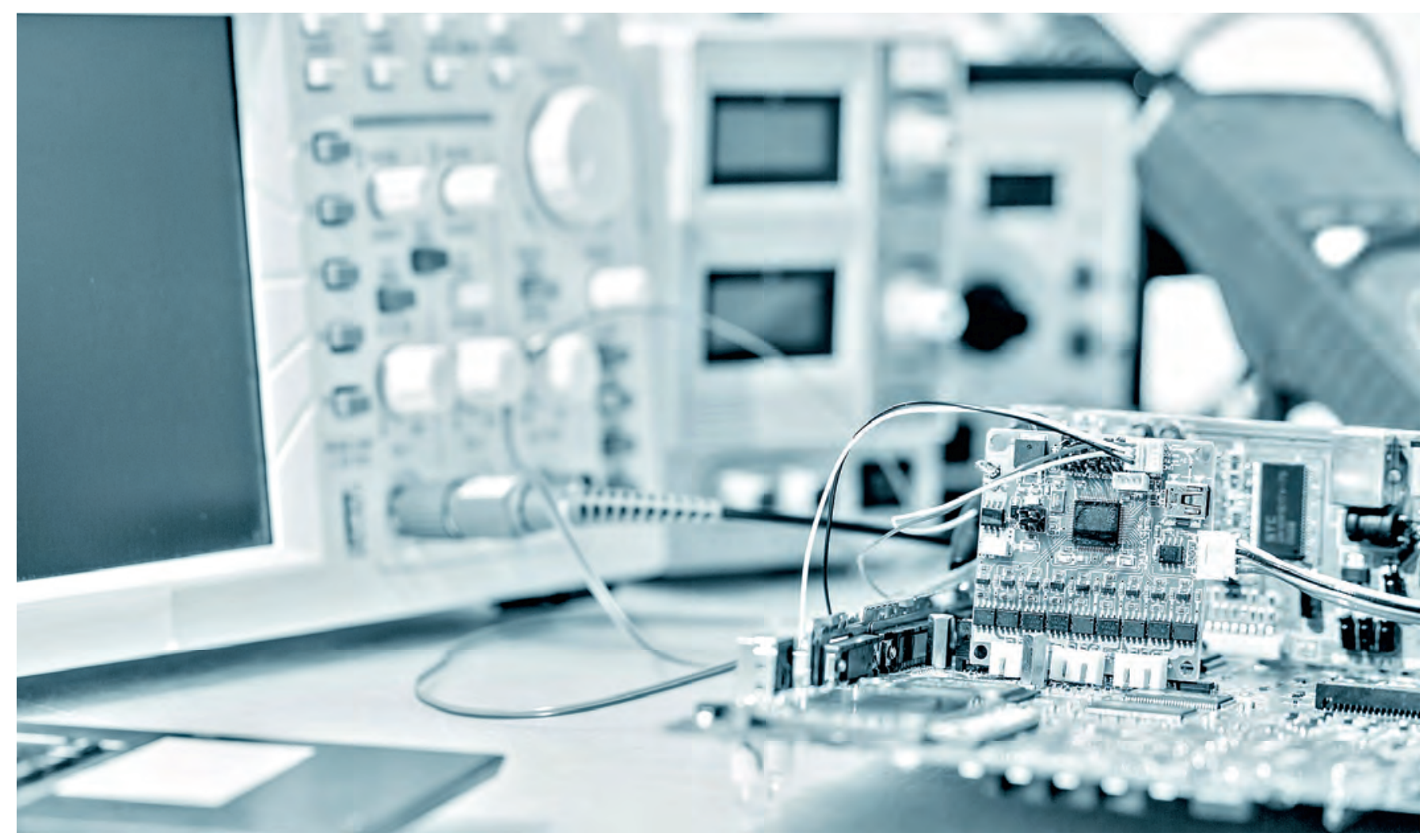

Программа III Всероссийской конференции по аналитической спектроскопии с международным участием ("Краснодар-2019») включала круглый стол на тему “Совершенствование инструментальной базы химического анализа в России - проблемы и перспективы» под председательством д. Т. н. В.А. Лабусова. Обсуждение вышло за рамки конференции продолжаем дискуссию на страницах нашего журнала.

Аналитические приборы - важнейший сегмент современного приборостроения, в котором используются самые последние достижения электроники, информации, материаловедения и других направлений научно-технического прогресса. Аналитическое приборостроение можно сравнить с современной медицинской диагностикой, без которой представить современную медицину невозможно. Следует отметить, что традиционно отечественное приборостроение отставало от зарубежного за исключением производства приборов военно-промышленного применения, хотя в отдельные периоды времени были исключения. Так, сразу после окончания Великой Отечественной войны по Постановлению Правительства все мощности, связанные с созданием вооружений и военной техники, были переданы для производства приборов спектрального анализа, и долгое время отечественное оборудование в этой области считалось лучшим в мире. Позднее все эти преимущества были утеряны, а после развала Советского Союза современное отечественное аналитическое приборостроение практически перестало существовать. 
Сегодня поднимается вопрос о возрождении производства в России отечественных приборов, предлагаются различные способы решения поставленных задач.

Каковы оптимальные пути развития отечественного аналитического приборостроения? Что для этого нужно сделать? Как связана эта работа с реализацией национальных проектов развития России?

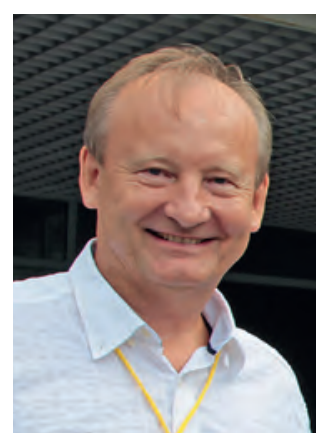

\section{Владимир Александрович Лабусов}

д. т. н., зав. иаб. оптических информационных систем ИАиЭ СО РАН, зав. кафедрой оптических информационных технологий НГТУ, тех. директор ООО «ВМК-Оптоэлектроника»

На примере нашего предприятия "ВМК-Оптоэлектроника" могу отметить следующие проблемы разработчиков и производителей аналитических приборов. Покупатели аналитических приборов предприятия "ВМК-Оптоэлектроника" находятся в основном в России, хотя мы продаем свою продукцию также в Казахстане, Узбекистане и ряде других стран. Сегодня в России узкий рынок аналитических приборов из-за малого количества активно работающих предприятий. До 2014 года наблюдался рост экономики и шло обновление аналитического оборудования. Сейчас экономика в упадке, а в кризис предприятия экономят на развитии. Малый спрос ведет к низким объемам производства и, как следствие, к увеличению цен на отечественные аналитические приборы.

Зарубежные производители тоже не могут похвастаться большими объемами продаж в России, но наш рынок для них не основной и не определяет их экономическое состояние.

С высоких трибун много говорят об импортозамещении, но мы не ощутили увеличения продаж наших аналитических приборов. Продолжаются закупки зарубежных приборов, имеющих российские аналоги. Отчасти в этом виноват и наш менталитет: "Зарубежное - значит лучшее".

Наш выход на зарубежный рынок затруднен из-за низких объемов выпускаемой продукции с ограниченными возможностями рекламных компаний, отсутствия опыта сертификации, логистики и организации качественного сервисного обслуживания за пределами страны. А главное, нас там никто не ждет, все защищают свой рынок.

Отечественные производители аналитических приборов в конкуренции с зарубежными на нашем полностью открытом рынке вынуждены выживать за счет существенного снижения цен или производства новых эксклюзивных приборов, которые не предлагают зарубежные компании. Однако производство такого оборудования требует немалых финансовых вложений и времени. От начала разработки до выхода на рынок нового аналитического прибора проходит около 5 лет.
Существует большое количество фондов поддержки инноваций, но мы этого не ощущаем. Их главные показатели публикации в высокорейтинговых, а значит, зарубежных журналах. Разработал коллектив прибор, внедрил его в производство, включил в Реестр средств измерений РФ - все это, к сожалению, не может сильно повысить его рейтинг. Считаю, что это не правильный подход. На первое место при оценке работы научно-технических коллективов нужно ставить достижения по внедрению полученных результатов в России.

Вот что рассказал о поддержке инноваций в США мой товарищ, у которого малое предприятие в Бостоне. Развитие новых технологий в США (в Западной Европе примерно так же) стимулируется следующим образом:

- прибыль предприятия, потраченная на исследования и разработки, не облагается налогами;

- при покупке на эти средства оборудования и комплектующих не берется налог с продаж (6-12\% от штата к штату);

- есть фонды на уровне города или штата, которые на каждую тысячу долларов затрат на исследования добавляют такую же сумму, то есть удваивают средства на развитие новых технологий.

При этом все базируется на некотором доверии. Отчетности практически нет.

Нам бы такие условия. Но боюсь, что, дав толику от этого, нас замучают отчетами и проверками.

Мог бы предложить такой вариант поддержки. Мы вкладываем свои средства в разработку прибора с положительным результатом. Как известно, финансовые затраты на разработку в 10 и более раз выше стоимости самого прибора. Пусть государство выделит средства на покупку хотя бы двух приборов для аналитических лабораторий, взяв с них обязательство разработать новые методики и опубликовать статьи об аналитических возможностях нового оборудования.

Теперь о перспективах. На конференции по аналитической спектроскопии от Института автоматики и электрометрии СО РАН и предприятия "ВМК-Оптоэлектроника" мы представили две новые разработки: атомно-абсорбционный спектрометр с электротермической атомизацией «ГрандААС" и атомно-эмиссионный спектрометр с микроволновой плазмой «Гранд-СВч».

Плазма "Гранд-СВч" имеет осесимметричную форму, аналогичную факелу ИСП, что позволяет в широких пределах регулировать мощность плазмы и анализировать высокосолевые растворы с общей минерализацией до 10\% 
масс. Определение элементов ведется одновременно, что существенно ускоряет анализ. Эти особенности выгодно отличают наш прибор, например, от спектрометра с микроволновой плазмой Agilent MP 4210.

Если в области атомно-эмиссионного анализа одновременным определением элементов никого не удивишь, то атомно-абсорбционный спектрометр "Гранд-ААС" - первый прибор в мире, способный определять методом электротермической атомно-абсорбционной спектрометрии десятки элементов одновременно, что может сделать этот метод экспрессным. Учитывая, что объем пробы спектрометра "Гранд-ААС" составляет 20 мкл, очевидно, что наиболее эффективное применение он может найти в фармацевтике, криминалистике, а также при анализе уникальных артефактов.

Я вижу перспективу во внедрении этих приборов в аналитическую практику, что приведет к ускорению химического анализа жидких проб. Спектрометр "Гранд-ААС" может быть востребован на зарубежном рынке, так как таких приборов там нет.

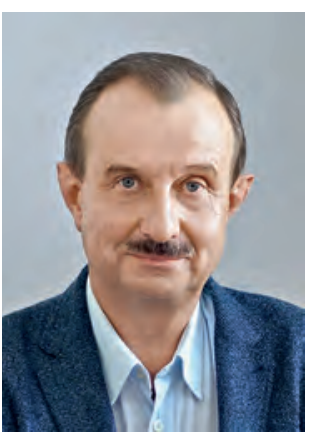

\section{Евгений Анатольевич Новиков}

к.х.н., генерапьный директор ООО «СокТрейд Ко», научный comрудник РГУ Нефти и Газа им. И.М. Губкина

\section{Screw it! Let's do it!"}

Сказал известный предприниматель Ричард Бренсон. На этот вопрос "Что нужно сделать?» он отвечал просто: «Нужно делать!».

Как делать - это уже другой вопрос. И на него уже давно есть ответы. Делать так, как делали люди, добившиеся успеха. Для меня примером идеального производителя аналитических приборов всегда была компания Hewlett Packard. Историю ее успеха описал Девид Паккард в книге The HP way. Хьюлет с Паккардом начинали с гаража, где они собрали свой первый аналитический прибор. Потом по одному добавляли новые продукты, увеличивали сбыт, покупали оборудование, нанимали людей. Подобным же образом, от малого к большому, начинали и Джобс с Возняком (тоже в гараже!) и Элмер с Перкиным, и многие другие. Никаких дотаций они не просили и ни в каких национальных проектах не участвовали. Паккард, кстати, не был сторонником кредитов. Его лозунгом было Pay as you go, то есть "Развивайся на заработанное".

Мы в компании “СокТрейд" пытаемся идти тем же путем. Начали около 10 лет назад с разработки одного прибора установки для дистилляции тяжелых нефтяных остатков при пониженном давлении, ГОСТ Р 50837.6, ASTM D1160. Разработка многократно себя окупила, продано более 30-ти аппаратов. Сейчас собираем установку шестого поколения с цветным сенсорным дисплеем. В планах выпуск еще нескольких новых приборов.

Меня давно уже вдохновляет наличие на рынке множества готовых компонентов для производства. Модульные спектрометры - пожалуйста! Компоненты для микрофлюидики - без проблем! Любые корпуса, насосы, детекторы, датчики, приводы, оптика - все есть. И все можно купить на мировом рынке. Любой прибор можно собрать, было бы желание.

Так что же мешает? Высокие налоги? Ерунда! Индивидуальный предприниматель платит всего 7\% налогов. Нигде в мире больше такого нет. Берись и делай! Строй производство по кирпичику и зарабатывай!

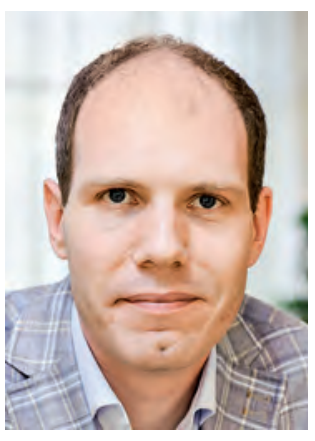

\section{Евгений Вячеславович Горский}

к. т.н., генеральный директор

ООО «Троицкий инженерный центр»

Начну с того, что, будучи разработчиком и производителем отечественных приборов, имею моральное право всех нас

Русский перевод: Ричард Бренсон “К черту все! Берись и делай!». Изд.: Манн, Иванов и Фербер, 2018.

D. Packard. The HP Way. How Bill Hewlett and I Built Our Company. HarperBusiness, 1996. немного поругать. Нужно признать, что за редкими исключениями, наши приборы не дотягивают до мирового уровня. Причем, в первую очередь, не по базовым метрологическим характеристикам, а по эргономике, удобству использования, надежности, качеству программного обеспечения, широте доступных аксессуаров и расходных материалов, сервисному обслуживанию, документации и обучающим руководствам и т.д. К сожалению, государственные программы поддержки самих приборостроителей никак эту проблему не решают, поскольку ставят своей целью разработку нового оборудования или методик без какой-либо связи этого процесса с рыночными реалиями.

И тут мы приходим к главной проблеме. На мой взгляд, в корне неверно рассматривать российский рынок аналитического оборудования изолированно: 
это всего лишь очень маленькая часть рынка мирового. Глобальные поставщики оборудования, при объемах производства на порядки выше, чем у локальных игроков, имеют возможность снижать себестоимость продукции, увеличивать норму прибыли и часть ее инвестировать в развитие продуктов и сервиса. С уровнем производства 5-20 машин в год, если это не эксклюзивный прибор стоимостью порядка миллиона долларов за единицу, очень сложно построить регулярный бизнес, сконцентрированный на доведении продукта до идеального состояния и его дальнейшей сервисной поддержке. Конечно, в какой-то мере это возможно, но у мировых брендов все равно будет преимущество. И если мы не говорим об уникальных, нишевых решениях, для которых всегда есть свое место на рынке, то не стоит делать импортозамещение самоцелью. К примеру, не нужно ставить задачу сделать российский ІСР-спектрометр. Цель должна быть такой: разработать ІСР-спектрометр, который станет востребованным в России, благодаря конкурентным характеристикам, привлекательной цене и, возможно, лучшим сервисным программам, адаптированным к российскому потребителю. Если прибор будет удачный, то при правильном выстраивании маркетинговой политики его также захотят приобрести коллеги из-за границы.
Мы как производители должны понимать, что рынок сейчас насыщен аналитическим оборудованием, в основном импортным. Кроме того, сотни и тысячи единиц приборов уже простаивают в университетах и академических институтах - растет предложение бывшего в употреблении оборудования. Казалось бы, у отечественных приборов в России и так масса преференций в сравнении с импортом: нет затрат на пошлины, логистику и импортный НДС, действуют преимущества при государственных закупках..., но покупатели все равно выбирают импорт. Надо постараться, чтобы заказчик захотел купить именно отечественный прибор. Необходимо обращать внимание на программное обеспечение, расходные материалы и сервисное обслуживание - пользователь сегодня привык кготовым комплексным решениям.

Разумеется, для достижения этих целей можно и нужно использовать все возможные меры поддержки, в том числе и государственной. Но конечная цель - разработка и внедрение на рынок оборудования, которое дальше будет успешно продаваться без какой-либо поддержки, причем не только внутри границ нашей страны.

Мнения других участников дискуссии читайте в следующем номере журнапа.

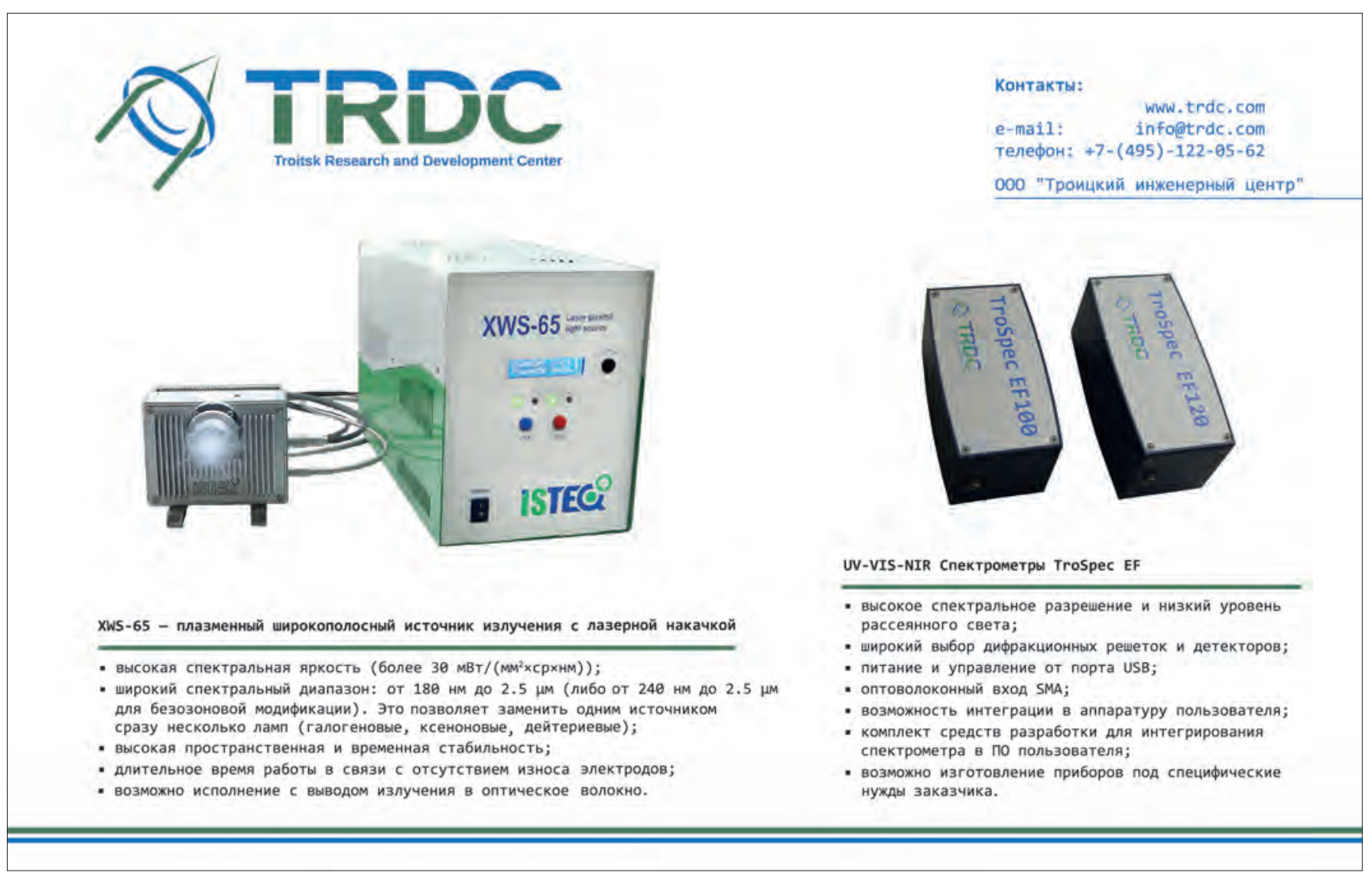

